\title{
Aspectos retóricos da ária Quia respexit humilitatem, do Magnificat em Ré maior de J. S. Bach BWV 243
}

Isabela de Figueiredo Santos (UFMG)

isabelacantora@gmail.com

Resumo: A Retórica teve um papel essencial na produção artística do século XVI ao século XVIII ao ditar sistematicamente a estruturação formal e a utilização de elementos figurativos em um discurso para fortalecer sua eloqüência. No caso da música se dá através da estruturação e divisão da música e da utilização de figuras retórico-musicais como, por exemplo, as catabasis (movimento melódico descendente) e anaphoras (repetição geral), entre outras. Este artigo pretende analisar alguns elementos da retórica contidos na ária Quia respexit humilitatem, composta por J. S. Bach.

Palavras-chave: análise retórica, figuras retórico-musicais, barroco, Quia respexit humilitatem, Bach.

Rhetorical aspects of the aria Quia respexit humilitatem, from Magnificat in D major by J. S. Bach BWV 243

Abstract: Rhetoric had an essential role in artistic production from the sixteenth to the eighteenth century by systematically dictating the formal structure and utilizing figurative elements in discourse to strengthen its eloquence. In the case of music, it occurs through structure and division of the music and the use of rhetorical-musical figures such as catabasis (descending melodic movement) or anaphora (general repetition) among others. This article aims to analyze some of the rhetorical elements contained in the aria Quia respexit humilitatem, composed by J. S. Bach.

Keywords: rhetorical analysis, rhetoric-musical figures, baroque, Quia respexit humilitatem, Bach.

\section{1- Introdução}

Objeto de estudo:ária para soprano Quia respexithumilitatem, do Magnificat em Ré maior, BWV 243, de J.S. Bach (1685 - 1750), composto para coro a 5 vozes e orquestra.

\section{2- Locus histórico}

A primeira apresentação do Magnificat foi na celebração de Vésperas do Natal de 1723. Bach tinha 38 anos e foi seu primeiro Natal em Leipzig. Curiosamente, a peça foi estreada na tonalidade de Mi bemol, ${ }^{1}$ revisada posteriormente e apresentada em sua tonalidade final (Ré maior) em 1732 (WIKIPEDIA e BACH, [1924]).

\section{3- Magnificat}

Segundo o DICIONÁRIO ELETRÔNICO HOUAISS DA LÍNGUA PORTUGUESA 1.0 (2001), o significado de Magnificat, do latim "enaltece, exalta, louva", tem duas rubricas. Do ponto de vista da religião: cântico entoado por Nossa Senhora quando da Anunciação, em que ela louva o Senhor e expressa agradecimentos pelas magnificências que the foram concedidas. Do ponto de vista da música: composição ou cântico inspirado nesse canto da Virgem Maria.
0 texto deste Magnificat foi extraído do Evangelho de São Lucas, capítulo 1, versículos 46 a 55 e trata do momento seguinte à Anunciação do anjo Gabriel em sua aparição à Maria. 0 texto da ária Quia respexit humilitatem é o versículo 48. Sua tradução é: "Porque Ele voltou os olhos para a humildade de sua serva. Doravante me dirão abençoadas todas as gerações".

\section{4- Contextualização}

0 anjo visitou primeiro Zacarias, marido de Isabel (parenta de Maria) e Ihe contou que sua mulher estava grávida de um menino. Ele deveria ser chamado de João - futuramente conhecido por João Batista. 0 anjo profetizou que João abriria o caminho para a vinda do filho de Deus e converteria muitos fiéis ao cristianismo. Zacarias não acreditou. A sua mulher era estéril e, além disso, ambos eram idosos. Por não crer na boa nova, foi emudecido pelo poder divino até o nascimento de seu filho, mas explicou a graça recebida através de gestos e escritos em uma tabuinha.

Após 6 meses, Maria também recebe a visita do anjo Gabriel avisando-a que dela nascerá o filho de Deus, 
Jesus. Ela não se considera digna, mas o anjo a conforta. Maria fica exultante. Nesta visita o anjo conta que à Isabel também foi concedida uma graça, estava grávida de 6 meses. Naqueles dias então, Maria se levanta e vai até a casa de Isabel, que ao Ihe ver exclama: "Bendita és tu entre as mulheres e bendito é o fruto do teu ventre" (A BÍBLIA DE JERUSALÉM, 1985. p.1928). A resposta de Maria à saudação de Isabel é o texto do Magnificat escrito por Lucas no trecho citado do livro de seu evangelho.

\section{5- Retórica na música}

A retórica foi uma disciplina muito significativa na vida artística da Europa nos séculos XVI, XVII e XVIII. Estudava desde a produção até a análise da eloqüência e persuasão dos discursos. De 1535 a 1792 diversos tratados retóricomusicais foram escritos, eram chamados "musica poetica" (CANO, 2000, p.7). Este artigo faz uma análise de elementos retórico-musicais da ária Quia respexit humilitatem, composta no séc. XVIII, no período alto barroco. Nesta época o processo composicional era baseado nos tratados de "musica poetica", com intuito de comover e persuadir o ouvinte através de recursos que simbolizam musicalmente os afetos. "Uma retórica musical sugere uma visão da música como discurso, ancorando-se na idéia de figuras da retórica musical" (PIEDADE, 2007.).

A criação artística de uma música utilizando tratados retóricos seguia um processo dividido em três etapas: inventio (escolha dos materiais a serem utilizados), dispositio (disposição dos materiais) e elocutio (execução e interpretação do material coletado e organizado). Neste artigo será abordado apenas a inventio e dispositio, uma vez que não tratarei aqui de questões interpretativas, próprias da elocutio.

Inventio - o autor identifica os argumentos musicais apropriados para a peça, como o tema da obra, a tonalidade, instrumentação, figuras retórico-musicais, tipo de textura e os afetos predominantes.

Dispositio - Como o nome sugere, é a disposição, organização do material coletado na inventio e é dividida, geralmente, em seis partes: exordium (introdução à matéria), narratio (parte que discorre sobre a matéria), propositio (parte onde se anuncia a proposta da matéria a ser defendida), confutatio (defesa da matéria, onde os argumentos são apresentados), confirmatio (confirmação da matéria) peroratio (anunciação de conclusão), podendo estas seções serem manuseadas em favor da intenção desejada pelo compositor.

\section{6- Sobre a ária}

A ária foi escrita para soprano, oboé d'amore obligato e baixo contínuo cifrado. Essa instrumentação de densidade rarefeita contribui para retratar a humildade da serva citada no texto. Apesar de ser de um momento de júbilo, foi escrita como um Adágio em Si menor, ${ }^{3}$ que, segundo Charpentier é um tom melancólico e só, segundo Mattheson é bizarro e amoroso, e segundo Rameau é doce e tenro (TARLING, 2000. p.5 e 7). Quando o texto se refere à bênção de Maria ocorre uma modulação passageira para o tom de Ré Maior. As figuras retóricas predominantemente remetem à humildade através de catabasis, passagem musical com direção melódica descendente, assim explica Kircher (citado por BARTEL, 1997. p.215):

A catabasis ou descensus é uma passagem musical através da qual podemos expressar afetos opostos aos da anabasis, tais como servidão e humildade, assim como afetos baixos e vis, como em 'Eu sou, contudo, imensamente humilhada' (Massainus), ou em 'A vida desceu ao inferno' (Massentius), ([Tradução feita por André Oliveira] apud OLIVEIRA, 2006. p.361).

Existem três palavras-chave no texto desta ária: humilitatem (humildade), ecce (eis) e beatam (abençoada). Cada uma delas tem seu sentido enfatizado por figuras retórico-musicais, como as catabasis para humildade ou movimentos ascendentes para a palavra "eis", como quem aponta uma direção. A palavra beatam é a única que tem uma sílaba prolongada: no c.22 em uma nota com duração de 2 tempos (mínima) e no c.24 com um melisma de 10 semi-colcheias.

\section{7- Análise Retórica}

A Tab.1 mostra as seções da dispositio da ária Quia respexit humilitatem, do Magnificat em Ré maior de J. S. Bach BWV 243.

\begin{tabular}{|c|c|c|}
\hline Seção & Compassos & Número de compassos \\
\hline Exordium & 1 a 5 & 5 \\
\hline Narratio & 6 a 10 & 5 \\
\hline Confirmatio I & 11 a 14 & 4 \\
\hline Confirmatio II & 15 a 17 & 3 \\
\hline Confutatio & 18 a 24 & 7 \\
\hline Peroratio & Omnes generationes (completo) & 27 \\
\hline
\end{tabular}

Tab.1 - Seções da dispositio da ária Quia respexit humilitatem, do Magnificat em Ré maior de J. S. Bach BWV 243 
Exordium (c.1-5) Introdução à matéria. Nesta parte 0 ouvinte é preparado para o discurso que virá.

A ária começa com uma introdução instrumental de caráter convocatório, instrumentada por uma melodia obligato do oboé d'amore acompanhada por baixo contínuo. A Partitio (ponto de partida) se dá com alusões à melodia a ser cantada pelo soprano no c.6 com algumas transformações (Fig.1 e Fig.2).

Segue abaixo o significado de algumas figuras retóricomusicais que aparecem no exordium (Fig.3). A maioria delas aparece por toda a peça.

Saltus Duriusculus - salto melódico dissonante de grande expressividade dramática. Neste trecho, é apresentado na figura dos schematoides - repetição de ritmo, frase ou melodia com alteração por aumentação ou diminuição da duração rítmica. Este salto inesperado gera uma certa tensão e prende a atenção do ouvinte. Anaphoras - Repetição geral; repetição da frase de abertura em passagens sucessivas; repetições de desenhos ritmicos e melódicos no baixo. Catabasis - Linhas melódicas descendentes - figuram a humildade de Maria nesta ária. Anabasis - Linhas melódicas ascendentes - aparecem na ária como compensação do movimento melódico, muitas vezes criando uma circulatio (série geralmente composta por oito notas, formando desenho de círculo ou onda).

0 terceiro e quarto tempos do c. 1 (oboé) apresenta uma imitação do gesto humano, quando o movimento de grau conjunto seguido de saltus duriusculus figura o gesto de "voltar os olhos" citado no texto (mimese). A tonalidade do exordium é Si menor.

Narratio (c.6-10) Parte que discorre sobre a matéria. Geralmente é uma parte objetiva, sem digressões ou desvios. Sua função é fixar um marco preparatório para a argumentação.

A melodia apresentada inicialmente pelo oboé aparece ornamentada na voz do soprano solista, sendo que cada um manterá o seu próprio perfil desta melodia introdutória. A palavra humilitatem aparece figurada pela catabasis e repetida como emphasis (passagem musical que enfatiza ou enaltece o significado do texto). Esta é uma palavra-chave do texto e carrega também as figuras retórico-musicais:

Hypotyposis - vívida representação de imagens encontradas no texto, no caso, o gesto de submissão e devoção de Maria.

Polyptoton - repetição de passagem melódica em

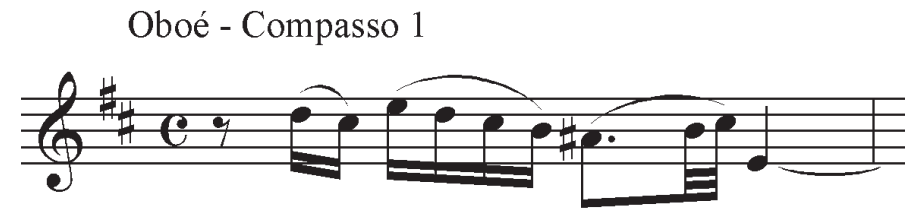

Fig.1 - Primeira frase do oboé

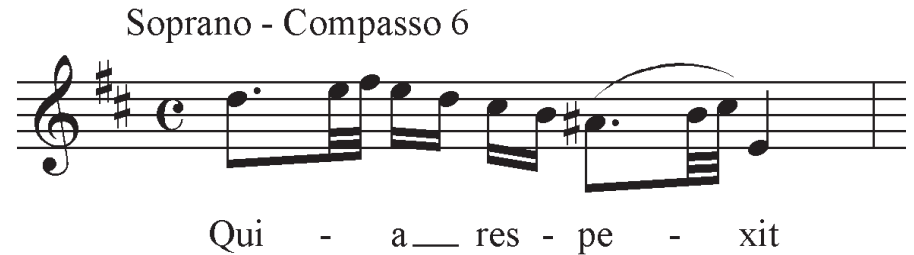

Fig.2 - Primeira frase do canto.

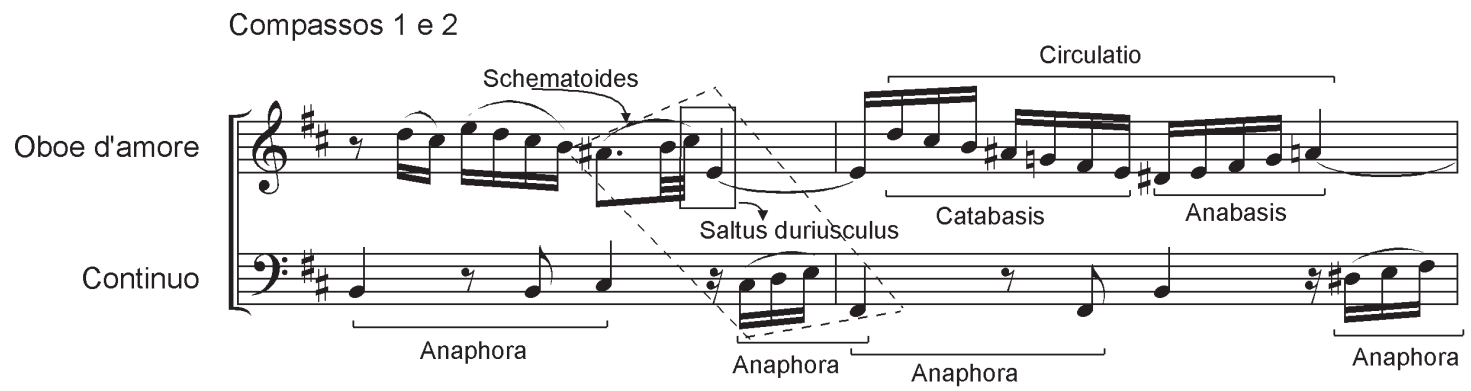

Fig.3 - Saltus duriusculus, schematoides, anaphora, catabasis, anabasis, circulation. 
diferentes alturas.

As ligaduras apresentadas nesta palavra (humilitatem) trazem a articulação de uma suspiratio ${ }^{4}$ em direção descendente (Fig.4).

Durante toda a ária encontramos as figuras heterolepsis e metabasis, que são, respectivamente, intrometimento de uma voz na região da outra e cruzamento de vozes (no sentido de uma completar a outra), o que dá mais unidade e constância melódica a esta música (Fig.5).

Nos c.8-9 (Fig.6) o oboé apresenta circulationes (desenho circular ou em forma de onda) em anaphora e gradatio (aumento ou ascensão gradual no som e altura/registro, criando intensidade crescente), com desfecho em material temático (saltus duriusculus e grande circulatio). Nos c.8- 9 temos a sensação de um leve afastamento para outra região tonal, no caso, a subdominante de Si menor, Mi menor.

Confirmatio I (c.11-14) Provas confirmativas, alusão à narratio. Onde o orador reexpõe sua matéria com maior carga afetiva.

0 c. 11 começa com a mesma frase do c.6 (início da narratio), porém a última nota deixa de ser um saltus duriusculus. A melodia anterior (c.6) termina na dissonância de sétima da dominante (Mi natural) e no compasso presente termina consonante, na tônica da dominante (Fá\#), num salto de $5^{a}$ justa. A maioria das edições preserva a frase do soprano idêntica, com o mi no final, como, por exemplo, na edição de Richard Walters (WALTERS, Comp. e Ed., 1994. p.28-30), mas em outras edições mais confiáveis, como Eulenburg $\left(\mathrm{BACH}_{1} \text { [1924]) }\right)^{5}$ e Lea Pocket Scores (BACH, 1959.), encontra-se o Fá\#, musicalmente mais interessante do que a repetição da frase do soprano sem nenhuma alteração.

Esta seção funciona como confirmação: o perfil melódico,

Soprano - Compassos 7 e 8

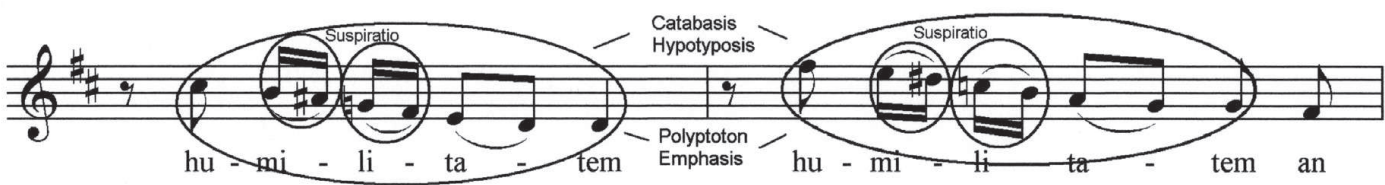

Fig.4 - Suspiratio, catabasis, hypotyposis, polyptoton, emphasis.

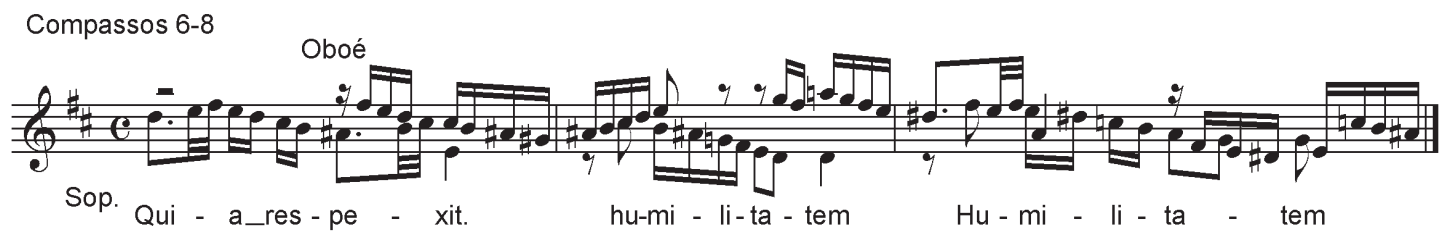

Fig.5 - voz e oboé sobrepostos: heterolepsis e metabasis.

Oboé - Compassos 8 e 9

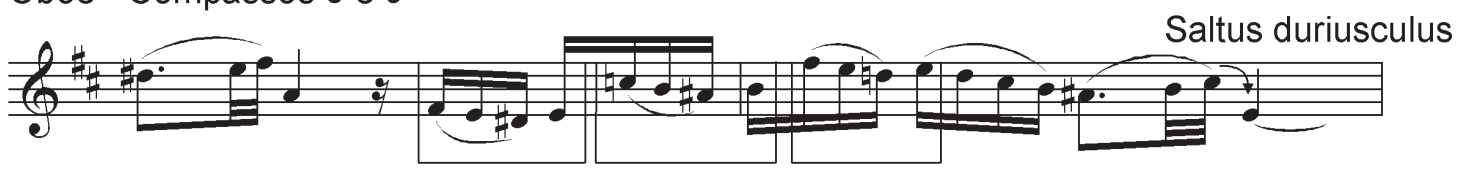

Circulatio em anaphora e gradatio

Fig.6 - Circulatio em anaphora e gradatio e desfecho em saltus duriusculus. 
ritmos e figuras retóricas são recapitulados, porém, nesta seção, a música passa da tonalidade de Si menor representante dos afetos já citados ao tratar da humildade de Maria - para a tonalidade de Ré Maior, ao falar de sua benção que será proferida por todas as gerações. A tonalidade de Ré Maior é citada por Rousseau, Charpentier, Mattheson e Rameau como algo grandioso, alegre ou de regozijo. A mudança dos afetos torna-se clara no fim da sentença ancilae suae, que no c.9, termina sob o efeito suspensivo da dominante de Si menor (Fá\#7) e no c.14 aparece resolvendo a harmonia em Ré maior. No último compasso desse confirmatio o oboé apresenta o material melódico da seção seguinte.

Confirmatio II (c.15-17): essa é uma parte instrumental em que o oboé apresenta material melódico constituído da junção de alguns materiais melódicos já apresentados em todas as seções anteriores (Fig.8). 0 baixo permanece com suas anaphoras. No c. 15 temos na melodia do oboé uma breve catabasis, um salto e uma pequena anabasis, juntando assim vários elementos numa só frase. A harmonia fica vagando entre as duas tonalidades apresentadas ( $\mathrm{Si}$ menor e Ré maior), o que faz desta seção uma sintese de todo o discurso musical apresentado até o momento.

Confutatio (c.18-24): Seção onde ocorre a defesa dos argumentos, parte mais elaborada e defesa da matéria. Aqui ocorre finalmente a resolução da harmonia na tonalidade de Ré maior, marcando um ponto de articulação formal na peça. Há um adensamento rítmico entre as três linhas e novos materiais se apresentam na linha vocal. A figura da epizeuxis (imediata e enfática repetição de palavra, nota, motivo ou frase) aparece de maneira mais estrita (c.18) entre o baixo e o oboé com a célula da melodia introdutória. No canto, na palavra ecce, temos o contraste do gesto de "voltar o olhar" (Fig.9; retratado na narratio pela célula de grau conjunto em fusa seguida de salto) com o gesto de "apontamento" (Fig.10) ao substituir o salto pela repetição da nota final. Um novo material musical é trazido com o texto ecce

\section{Compasso 6}

\section{Compasso 11}

Oboe d'amore

Soprano

Continuo

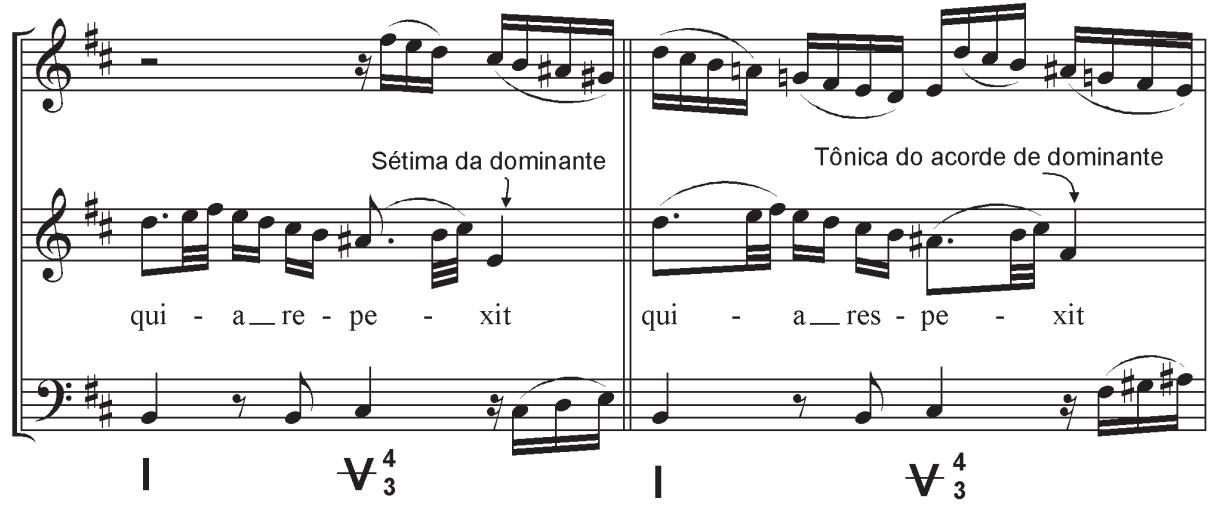

Fig.7 - Soprano, oboé e contínuo: diferentes resoluções do primeiro motivo cantado.

Oboe d'amore
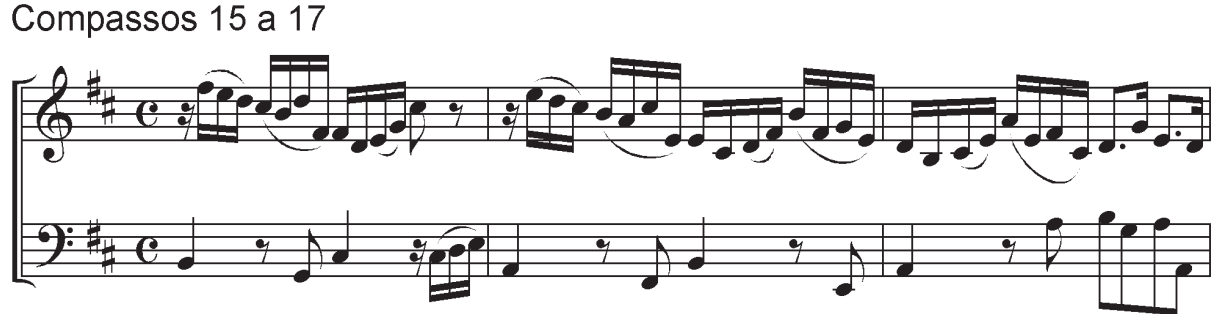

Fig.8 - Junção de materiais melódicos no oboé, anaphoras no baixo e harmonia entre Si menor e Ré maior.

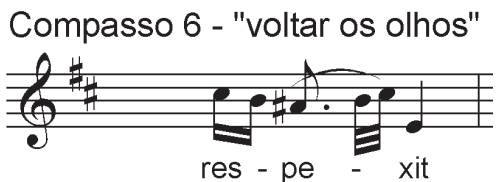

Fig.9 - "Voltar os olhos"

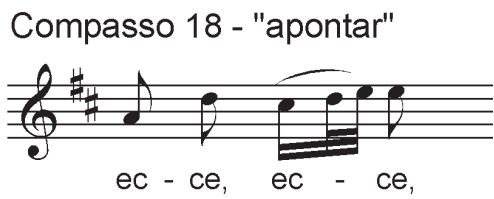

Fig.10 - "Apontar" 
enim ex hoc beatam (c.20-21) repetido como polyptoton ${ }^{6}$ e epizeuxis. ${ }^{7}$ Tantas novidades fazem desta seção a parte mais rica e elaborada, característica própria da confutatio.

Do c.22 em diante há uma dubiedade entre a parte instrumental e a voz. A voz, analisada separadamente, leva a crer que estamos diante da peroratio (sentença final), porém o baixo retoma suas anaphoras e o oboé volta a apresentar as catabasis predominantes no exordium e na narratio, o que leva a crer que o c.22 se trata apenas de uma divisão de seção dentro da confutatio.

Peroratio - Omnes generationes (27 compassos) Sentença final. Nesta seção algumas vezes enuncia-se os mesmos temas já apresentados, em outras, como é o caso desta ária, recorre-se a outro tipo de material para enfatizar e convencer o discurso que foi apresentado anteriormente.

Tendo como referência o texto de São Lucas, a fala de Maria só se completa no movimento seguinte, omnes generationes (por todas as gerações), o que dá a ele a função de uma peroratio. 0 omnes generationes é escrito em forma de fuga para coro a 5 vozes, 2 flautas, 2 oboés d'amore, 2 violinos, viola e baixo contínuo (Fig.11). Segundo Bartel (1997, p.282), analisando o verbete 'fuga' escrito por Forkel (1749 - 1818), as numerosas linhas melódicas independentes de uma fuga expressam o sentimento de uma multidão, em contraposição com a linha melódica da ária, que expressa o sentimento de um indivíduo.

Omnes generationes

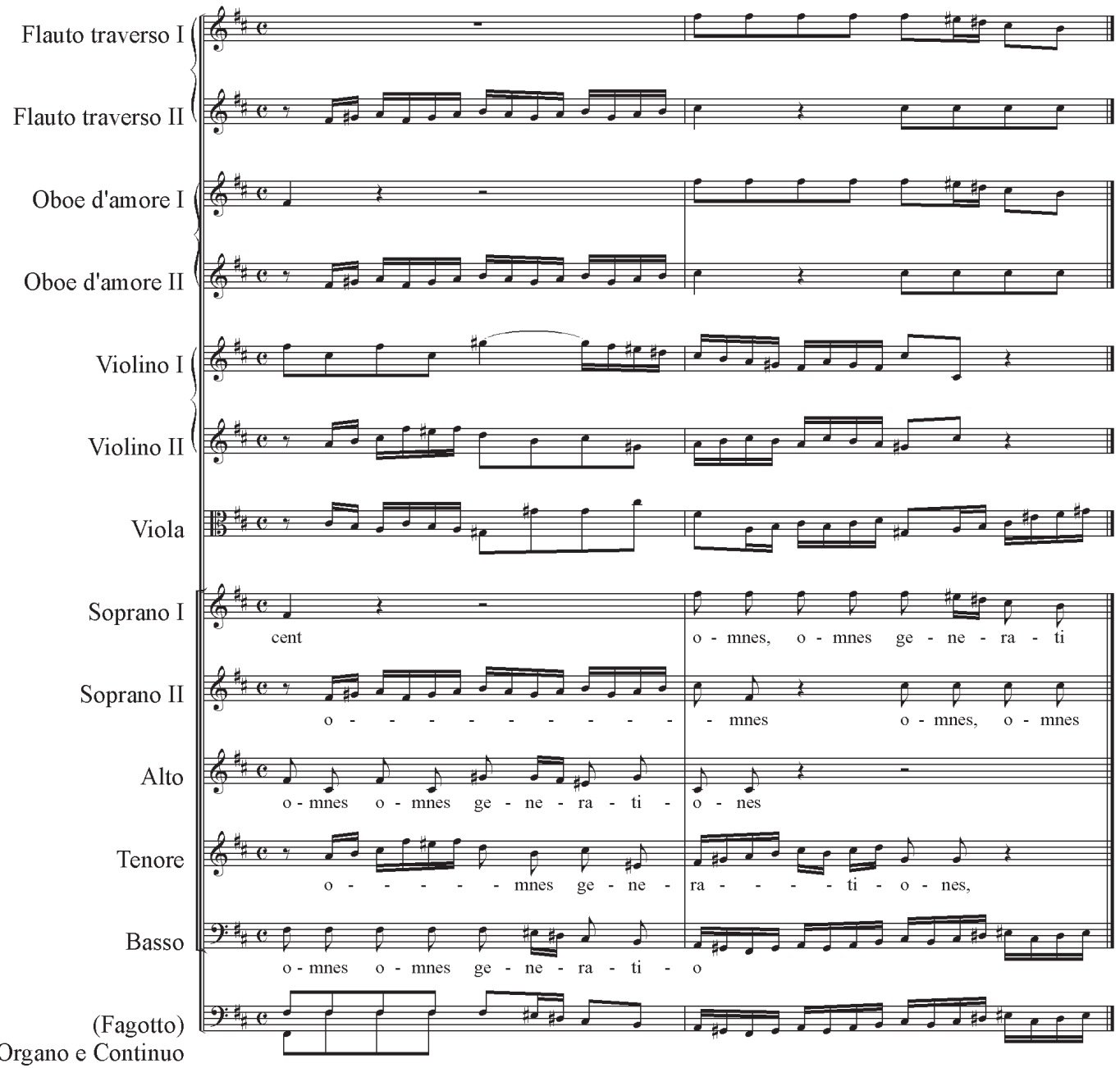

Fig.11 - Fuga em Fá\# menor com armadura de Si menor (mantida da ária que antecede). Última nota do 'Quia' em elisão com a primeira do 'Omnes'. 


\section{8 - Conclusão}

A análise desta peça sob os aspectos aqui apresentados contribui para uma melhor compreensão da obra Magnificat, BWV 243 e, conseqüentemente, para uma melhor e mais clara interpretação da mesma. Com esta análise, tornou-se claro que a passagem do evangelho de Lucas (1:48) foi dividida neste Magnificat em três partes, ${ }^{8}$ sendo duas delas pertencentes à ária e a última tratada como fuga no movimento seguinte.

A ária Quia respexit humilitatem é muito rica em figuras retórico-musicais e segue uma estratégia peculiar de organização do seu discurso retórico ao passar diretamente da Narratio para a Confirmatio, talvez pelo fato de que o texto não ofereça material para a construção de uma Propositio (enunciação da tese fundamental que se sustenta o discurso, comumente encontrada entre a Narratio e Confutatio).
Aúltima nota do 'Quia ' termina no primeiro tempo do 'Omnes', que foi escrito na tonalidade de Fá\# menor (armadura com 3 sustenidos). Bach, entretanto, manteve a armadura com 2 sustenidos (Ré maior ou Si menor), a mesma armadura da ária analisada, o que reforça ainda mais a idéia de que os dois movimentos estão intimamente conectados. Há um estudo que lida exclusivamente com a questão da unificação dos movimentos; Robert Camarota (2003), defende em seu artigo a idéia de que a ária e a fuga são, na verdade, um só movimento. Com a edição da partitura feita por Robert Franz em 1864, a fuga passou a ser executada em andamento mais rápido que a ária, mas antes disso a ária e a fuga estavam intrinsecamente conectadas e eram, juntas, o terceiro movimento. Na revisão da partitura feita por Bach em 1733 ele acrescentou a indicação 'adagio' no inicio da ária, estabelecendo este tempo para todo o movimento (CAMAROTA, 2003). ${ }^{9}$ Fica a cargo dos regentes e intérpretes decidir o andamento do 'omnes', uma vez que não entrarei neste mérito nesta pesquisa. 


\section{Referências}

A BÍBLIA DE JERUSALÉM. São Paulo: Edições Paulinas, 1985.

BACH, J. S.. Magnificat in D major, BWV 243. London: Edition Eulenburg No. 964. [1924]. Partitura com grade completa. BACH, J. S.. Magnificat in D major, BWV 243. New York: Lea Pocket Scores. 1959. Partitura com grade completa.

BARTEL, Dietrich. Musica poética: musica- rethorical figures in German Baroque Music. Lincoln, Nebraska, University of Nebraska Press, 1997.

CAMAROTA, Robert M., On the Performance of "Quia respexit ... omnes generationes" from J. S. Bach's Magnificat. 2003 Disponivel em <http://caliber.ucpress.net/doi/abs/10.1525/jm.2001.18.3.458?cookieSet=1CtjournalCode=jm> Acesso: 02 de junho de 2007.

CANO, Rubén López. Música y retórica em el barroco. Cidade do México, D.F.: Universidad Nacional Autônoma de México, 2000.

DICIONÁRIO ELETRÔNICO HOUAISS DA LÍNGUA PORTUGUESA 1.0. Instituto Antônio Houaiss, 2001. (CD-ROM)

OLIVEIRA, André. $O$ uso de figuras de Retórica Musical no Magnificat de Johann Sebastian Bach. XVI ANPPOM. Brasilia, 2006.

PIEDADE, Acácio Tadeu. Expressão e sentido na música brasileira: retórica e análise musical. Revista Eletrônica de Musicologia, Volume XI - Setembro de 2007. Disponivel em <http://www.rem.ufpr.br/REMv11/11/11-piedade-retorica. html> Acesso em: 29 de outubro de 2007.

TARLING, Judy. Baroque string playing for ingenious learners. St. Albans, UK, Corda Music, 2000.

WALTERS, Richard (Comp. e Ed.). The Oratorio Anthology (soprano).Hal Leonard Corporation. 1994. The Art Institute of Chicago. Partituras para piano e voz aguda.

WIKIPEDIA - Magnificat (Bach). Disponivel em < http://en.wikipedia.org/wiki/Magnificat_(Bach) > Acesso em: 20 de maio de 2007.

\section{Leitura Recomendada}

RIEMENSCHNEIDER BACH INSTITUTE. Disponivel em <http://www.bw.edu/academics/libraries/bach/library/kenney/pub/ magnificat/> Acesso em: 13 de junho de 2007.

Isabela Santos é soprano, bacharel em canto lírico pela Universidade Federal de Minas Gerais (UFMG) e mestranda em performance na UFMG, sob orientação de Margarida Borghoff. Estuda técnica vocal com o baixo-barítono americano Stephen Bronk. Como cantora, é ganhadora de diversos prêmios em concursos nacionais de canto e do prêmio Cantor(a) Jovem no $7^{\circ}$ Concurso Internacional de Canto Bidu Sayão.

\section{Notas}

Segundo Charpentier (1692), Mib maior é uma tonalidade cruel e hostil, e segundo Mattheson (1713-19), é patética e séria apud TARLING, 2000. p. 5 e 7 .

2 Tradução feita oralmente pelo regente e estudioso do latim Eduardo Fonseca.

3 Na inventio é feita a escolha da tonalidade.

Figura que simboliza "suspiros".

5 Nesta edição da Eulenburg, o musicólogo alemão Arnold Schering escreve considerações sobre o Magnificat e a edição, aqui traduzidas por mim: nenhum erro foi encontrado na partitura da presente edição, a não ser pouquíssimas sutilezas, como a falta de uma barra de compasso e ligaduras de frase mais exatas. A voz e o violino foram transpostos para a clave usual atual. A partitura foi copiada fidedignamente da segunda versão da partitura original feita por Bach, já na tonalidade de Ré maior.

6 Repetição de passagem melódica em diferentes alturas.

Imediata e enfática repetição de palavra, nota, motivo ou frase.

Parte I: "Quia respexit humilitatem ancilae suae"; parte II: "Ecce enim ex hoc beatam me dicent"; parte III: "omnes generationes".

9 Informações retiradas do resumo do artigo de CAMAROTA, 2003. A seleção dos trechos, sintese e tradução foram feitas por mim. 